\title{
Shiitake, um cogumelo mutagênico ou antimutagênico?
}

\author{
Mushroom Shiitake, is it mutagenic or antimutagenic agent?
}

\author{
Cíntia Kaori Miyaji e llce Mara de Syllos Cólus²
}

\begin{abstract}
Resumo: Desde a antigüidade, os cogumelos vêm sendo consumidos pelos povos orientais devido às suas propriedades medicinais e comestíveis e ao longo dos anos tem-se observado um aumento gradativo no consumo também nos países ocidentais, inclusive o Brasil. No entanto, ainda há dúvidas quanto aos benefícios ou prejuízos à saúde, decorrentes do uso destes cogumelos pelas populações humanas. Entre os cogumelos muito apreciados na culinária brasileira, destaca-se o Shiitake (Lentinula edodes (Berk.) Pegler), um dos fungos comestíveis mais estudados quanto às suas propriedades funcionais e nutricionais. Já se tem conhecimento sobre várias atividades deste basidiomiceto superior, como antitumoral, antiviral, bactericida, regulador da homeostase e do biorritmo. No entanto, poucos trabalhos abordam suas propriedades mutagênicas e antimutagênicas em organismos procariontes e eucariontes e o conhecimento dessas propriedades biológicas são importantes para que um produto seja recomendável como alimento e/ou medicamento. Dessa forma, é prematura sua recomendação para a saúde humana, pois é necessário, para isso, a ampliação de estudos sobre as atividades mutagênicas e antimutagênicas do cogumelo Shiitake ou de seus compostos ativos.
\end{abstract}

Palavras-chave: Cogumelo comestível; Shiitake; Mutagenicidade; Antimutagenicidade.

\begin{abstract}
Mushrooms have been consumed by eastern populations due to their edible and medicinal properties, for a long time. Over the years, there has also been a gradual increase in the consumption of mushrooms in the western countries, including Brazil. However, the benefits or harms that these mushrooms may cause to the human health are still uncertain. Shiitake (Lentinula edodes (Berk.) Pegler) is one of the most appreciated fungi in the Brazilian cuisine and its functional and nutritional properties have been extensively studied. Other characteristics of this basidiomycet have also been reported, including its antitumoral, antiviral, bactericidal properties, as well as being a homeostasis and biorhythm regulator. However, studies regarding its mutagenic and antimutagenic potential in prokaryotic and eukaryotic organisms are scarce. Knowledge of these biological properties is essential before a product can be recommended as food and/or drug. Therefore, its indication as a beneficial product to human health is premature since it is necessary to broaden studies on the mutagenic and antimutagenic activities of the mushroom Shiitake or of its active compounds.
\end{abstract}

Key words: Eatable mushroom; Shiitake; Mutagenesis; Antimutagenesis.

Várias espécies de cogumelos têm sido avaliadas tanto por seu valor nutricional, quanto por suas propriedades farmacológicas, uma vez que são alimentos fisiologicamente benéficos e algumas espécies têm um forte efeito inibidor do crescimento de diferentes tipos de tumores. Entre as várias propriedades fisiológicas atribuídas aos cogumelos, temos: manutenção da homeostase, regulação do biorritmo, prevenção de doenças como o câncer e doenças do coração, redução da pressão arterial e diminuição do nível de colesterol no sangue (WASSER; WEIS, 1999).

De aproximadamente 10.000 espécies de cogumelos conhecidos, cerca de 700 são comestíveis e mais de 200 têm valor medicinal, embora uma pequena parcela desses cogumelos seja própria para consumo (CHANG, 1996). Normalmente os cogumelos comestíveis como Auricularia, Flammulina (enokitake), Grifola e Lentinula (Shiitake) têm propriedades importantes para o funcionamento vital do organismo humano. Entretanto, a maioria dos cogumelos comestíveis que tem tais propriedades não tem valor medicinal, como o Agaricus bisporus e alguns cogumelos medicinais como Ganoderma e Coriolus, não são comestíveis (CHANG, 1996).

Entre as espécies de cogumelos comestíveis, apenas 20 são comercialmente produzidas em alta escala, destacando-se entre elas o Agaricus bisporus (Champignon), Volvariella volvacea (Cogumelo de palha), Pleurotus ostreatus (Hiratake), Auricularia aurícula e Lentinula edodes (Shiitake) (CHANG, 1996).

O cogumelo Shiitake (nome japonês) tem sido referido desde 1877 por vários nomes científicos, sendo Lentinula edodes (Berk.) Pegler o mais aceito na atualidade (QUIMIO et al. 1990 apud MAKI, (1999). O termo "Berk" vem de Berkeley, que foi o primeiro a descrever a espécie, porém no gênero Lentinus. Pegler foi quem inseriu esta espécie no gênero Lentinula (MAKI, 1999). Molina et al. (1992) confirmaram, através de estudos de polimorfismo de fragmentos de restrição de DNA ribossomal ( $r D N A$ ) seguido de PCR, que o cogumelo Shiitake não pertence ao gênero Lentinus, e sim, ao Lentinula. Até então, era muito confusa a

\footnotetext{
${ }^{1}$ Mestre em Genética e Melhoramento pela Universidade Estadual de Londrina.

2 Profa. Dra. do Departamento de Biologia Geral da Universidade Estadual de Londrina.
} 
denominação de Shiitake, e os dois nomes científicos (Lentinus e Lentinula edodes) eram considerados corretos. Por este estudo os autores concluíram que o gênero Lentinula pertence à família Tricholomataceae (Ordem Agaricales).

O Shiitake foi cultivado pela primeira vez há cerca de 1000 anos na China, posteriormente no Japão, Tailândia, Coréia e Malásia. A população japonesa considera-o o elixir da vida, em função das suas propriedades terapêuticas e medicinais que já foram comprovadas (JONG; BIRMINGHAM, 1993). Este cogumelo comestível é muito consumido em todo o mundo, seja pelo seu paladar ou por suas propriedades medicinais. É o segundo cogumelo comestível mais produzido no mundo, estando atrás somente do Champignon, Agaricus bisporus (CHANG, 1996).

O Shiitake cru contém cerca de $90 \%$ de água e dentre os outros componentes, predominam o ergosterol ou pró-vitamina D, seguido por carboidratos, proteínas (26\% do peso seco), lipídeos (maior parte), fibras, minerais, vitaminas B-1 e B-2 (MIZUNO, 1995a).

Embora atualmente os cogumelos sejam utilizados em muitos países ocidentais como alimento e remédio, seu uso na manutenção da saúde é mais comum no Oriente, sendo os primeiros registros provenientes da China, cerca de 100 anos d.C. (CHANG, 1996). No entanto, ainda há dúvidas quanto aos benefícios ou prejuízos à saúde, decorrentes do uso destes cogumelos pelas populações humanas. Para que um produto seja recomendável como alimento e/ou medicamento, suas propriedades biológicas devem ser bem conhecidas. Entre os testes recomendados pelo Us Food and Drug Administration (FDA), destacam-se os relacionados às atividades mutagênicas $e$ antimutagênicas (FDA, 2001).

Dependendo do material genético que o agente mutagênico atinge, as manifestações das mutações serão diferentes, podendo até ter efeitos deletérios. Quando a mutação ocorre nas células somáticas, há várias conseqüências, sendo as mais comuns a formação de tumores benignos ou malignos; a morte celular, que pode causar envelhecimento precoce; mal formações e abortos, durante o desenvolvimento embrionário. Segundo De Flora (1998), há também evidências do papel das mutações na patogenia de doenças degenerativas crônicas, que são as principais causas de mortalidade na população humana. Quando as mutações ocorrem nas células germinativas podem originar alterações genéticas transmissíveis, levando a desordens genéticas, fertilidade reduzida, síndromes fetais que, por sua vez, podem originar malformações e até abortos (RABELLO-GAY, 1991).

Os dados relacionados à mutagenicidade do cogumelo Shiitake, assim como o da maioria dos cogumelos comestíveis são escassos e os resultados de experimentos com organismos procariotos e eucariotos parecem confirmar que, quando um cogumelo apresenta atividade mutagênica, ela é, em geral, variável (Tabela 1). Esse fenômeno é atribuído a vários fatores, entre eles, a composição química dos cogumelos, que é dependente das variações geográficas, sazonais e intraespecíficas (STERNER et al., 1982a, 1982b; GRUTER et al.,1991).

Miyaji (2001) encontrou resultados negativos para mutagenicidade de três concentrações distintas de um extrato aquoso do cogumelo Shiitake, preparado a $22^{\circ} \mathrm{C}$, em cultura de células de carcinoma epidermóide de laringe humana (HEp-2) frente ao teste do Micronúcleo (MN). Este é um teste citogenético sensível, que permite medir aberrações do tipo quebras e perdas cromossômicas em células interfásicas. Embora os micronúcleos possam ser originados espontâneamente, a sua indução é comumente usada para se detectar danos genotóxicos resultantes de exposição a agentes mutagênicos (HEDLLE et al., 1983). Os resultados com este teste indicam que o extrato de Shiitake não se comportou, nas condições experimentais utilizadas, como um composto clastogênico nem aneugênico.

Gruter et al. (1991) também encontraram resultados negativos quanto à mutagenicidade de um extrato metanólico do Shiitake frente ao teste de Ames. Este teste utiliza diferentes linhagens da bactéria Salmonella typhimurium e é um dos principais métodos desenvolvidos para se avaliar se um determinado composto químico ou misturas complexas induzem mutações no genoma dessa bactéria, pela reversão do fenótipo histidina negativo (his-) para histidina positivo $\left(\right.$ his $\left.^{+}\right)$, na presença ou ausência de sistemas metabólicos de ativação (S-9).

Outro teste utilizado por Miyaji (2001) para avaliar a mutagenicidade de extratos aquosos do Cogumelo Shiitake em células HEp-2 foi o Ensaio do Cometa. Este teste, na sua versão alcalina, detecta quebras de fita simples e sítios álcali-lábeis no DNA de células individuais (SPEIT; HARTMANN, 1999). Tal detecção é possível porque ocorre uma migração do DNA do núcleo, que é proporcional aos danos sofridos por ele, e a imagem obtida com esta migração se assemelha a um cometa com cabeça e cauda, por isso a denominação de teste do Cometa (KLAUDE et al., 1996). Miyaji (2001) não encontrou atividade genotóxica em somente 2 dos nove extratos testados, enquanto nos demais extratos foi detectada genotoxicidade em diferentes graus. Dois tipos de extratos aquosos apresentaram-se genotóxicos efetivos, enquanto os outros cinco apresentaram-se moderadamente genotóxicos.

A análise conjunta dos parâmetros temperatura e concentração mostrou que o efeito mutagênico do cogumelo foi atenuado quando a temperatura de preparo do extrato foi alterada de ambiente para gelada ou aquecida. Este dado reforça a afirmação de Sterner et al. (1982a) de que durante o processamento dos cogumelos para fins alimentícios, o aquecimento e a conservação dos fungos podem ter uma grande influência nas suas atividades biológicas. De fato, Morales et al. (1990) detectaram atividade mutagênica levemente maior em cogumelos congelados do que nos 
cogumelos frescos, sugerindo que compostos termolábeis ou voláteis possam estar envolvidos na mutagenicidade das espécies estudadas.

Chang (1996) considera que os cogumelos em geral têm por característica vários compostos com diversas atividades biológicas que podem variar de acordo com o seu modo de preparo e de consumo.

Os resultados um tanto antagônicos obtidos com amostras do cogumelo Shiitake frente aos testes de Ames (GRUTER et al., 1991), Micronúcleo e Cometa (MIYAJI, 2001) podem ser devidos a diferenças dependentes de habitat ou de cultivo. Segundo Eira (comunicação pessoal, 2000), se os procedimentos de cultivo e colheita forem realizados sob condições controladas, como, por exemplo, o uso de toras de eucalipto de primeiro corte, que apresentam uma disponibilidade nutricional maior do que as demais, e a realização da inoculação evitando a desidratação ou possível contaminação das toras, não interferirão nos resultados de mutagenicidade.

De acordo com Sterner et al. (1982a), mesmo depois de muitas espécies comestíveis serem identificadas como mutagênicas, parece prematuro fazer recomendações específicas sobre eventuais riscos à saúde humana antes que outras informações sobre a composição química e toxicologia dos compostos ativos sejam obtidas, assim como sobre os efeitos de vários métodos usados no preparo dos cogumelos como alimento.

Os dados da literatura em relação à mutagenicidade do cogumelo Shiitake sugerem a ampliação no número de trabalhos com esse fungo e/ou com seus compostos ativos, para esclarecer melhor os riscos que podem estar associados ao seu consumo. Isto porque, segundo as observações de Gruter et al. (1991), uma atividade mutagênica detectada em extrato, pode sugerir diferentes destinos do agente mutagênico como, por exemplo, se tornar instável sob condições normais da digestão ou não ser absorvido pelo trato gastrointestinal, ou ainda ser ativado a uma substância tóxica.

Alguns trabalhos relataram efeitos carcinogênicos de cogumelos cultivados, como o de Toth e Erikson (1986), que mostraram que o Champignon, Agaricus bisporus cru foi carcinogênico em animais de laboratório. O fato de que nenhum estudo demonstrou, até o momento, propriedade carcinogênica para o cogumelo Shiitake, somado ao número reduzido de estudos mostrando uma mutagenicidade efetiva desse cogumelo e ao aumento gradativo no interesse quanto à identificação de produtos naturais ou sintéticos que possam ter propriedades antimutagênicas ou anticarcinogênicas, a investigação da sua possível atividade antimutagênica, torna-se atraente.

Segundo Hartman e Shankel (1990), a antimutagênese pode ocorrer em diferentes níveis:

a) prevenção da formação de metabólitos mutagênicos;

b) captura dos agentes mutagênicos pelas enzimas ou pelos componentes celulares dos tecidos; c) neutralização das lesões pré-mutagênicas e

d) modulação dos mecanismos que aumentam a inativação metabólica de compostos mutagênicos.

O termo antimutagênico foi usado originalmente para descrever aqueles agentes que induzem redução da freqüência de mutações espontâneas ou induzidas, independentemente do mecanismo envolvido (WATERS et al., 1990). Verificou-se em vários estudos que substâncias endógenas obtidas por meio de alimentos, ou sintetizadas pelas células, exibem algum tipo de atividade inibitória a agentes mutagênicos naturais e artificiais (ODIN, 1997).

O descobrimento de produtos que reduzem a taxa de mutações fatalmente diminuiria a incidência de câncer, pois o homem poderia aumentar a exposição a determinados agentes antimutagênicos efetivos (HAYATSU et al., 1988), especialmente por meio da dieta (WATTEMBERG, 1985; RAMEL et al., 1986). Muitos estudos laboratoriais têm identificado um grande número de compostos antimutagênicos e anticarcinogênicos na dieta, a maioria presente nas plantas (KOHLMEIER et al., 1995 apudDE MARINI, 1998).

Entre os produtos naturais que apresentam potencial antimutagênico temos o repolho, alho-poró, frutas cítricas, ervas e condimentos; componentes de alimentos como as vitaminas A, C e E, flavonóides, compostos organo-sulfurados e componentes de óleos como o eugenol, presente no cravo e também em óleos essenciais de muitas outras plantas como a canela, o manjericão e a noz-moscada (ROMPELBERG et al., 1995). Dietas suplementadas com suco de cenoura, tomate ou espinafre, resultaram na redução de quebras de cadeia do DNA de linfócitos humanos avaliados pelo teste do Cometa. Foi encontrada também redução significativa de danos oxidativos devido ao suco de cenoura (POOL-ZOBEL et al., 1997).

De acordo com Lehmann et al. (2000), com o aumento do consumo de alimentos contendo componentes quimiopreventivos, pode ser possível melhorar a proteção contra danos causados por compostos mutagênicos e carcinogênicos. Este fato tem levado a um aumento no interesse da população sobre os possíveis efeitos antimutagênicos de produtos naturais ou compostos químicos e, conseqüentemente, a um incremento dos estudos nesta área.

Em geral, a investigação dos possíveis efeitos anticarcinogênicos dos cogumelos está bem documentada, pois, em aproximadamente 200 espécies de basidiomicetos superiores, foi detectada a atividade de inibição de diferentes tipos tumorais (MIZUNO, 1995a, 1995b).

As atividades antitumorais de alguns cogumelos como Coriolus versicolore Lentinula edodes parecem ser devidas à presença de polissacarídeos, que têm efeito antitumoral por meio da ativação do sistema imune e, por isso, são utilizados clinicamente como agentes imunoterapêuticos em pacientes com câncer (KURASHIGUE et al., 1997). 
O $\beta$-D glucan ou lentinan, o composto ativo do cogumelo Shiitake, foi identificado na década de 70 como sendo efetivo nos tratamentos de câncer. Isto acelerou estudos farmacológicos não só com o corpo de frutificação, como com os esporos, micélios incubados e produtos isolados, o que resultou na descoberta de várias substâncias ativas, além do lentinan, como por exemplo, o KS-2 e as glicoproteínas LEM e LAP entre outros (MIZUNO, 1995a). No entanto, a atividade dos princípios ativos do Shiitake pode ser influenciada pelo modo e o tempo de estocagem do cogumelo. Minato et al. (1999) observaram uma grande redução dos conteúdos de lentinan em cogumelos estocados a $20^{\circ} \mathrm{C}$, enquanto que tal conteúdo se manteve constante quando estocado a $5^{\circ} \mathrm{C}$ ou a $1^{\circ} \mathrm{C}$.
Estudos sobre a antimutagenicidade de cogumelos comestíveis ou medicinais são realizados, predominantemente, em células procariontes (Tabela 2) e há a necessidade de um incremento destes estudos utilizando também células eucarióticas. O uso de células de mamíferos in vitro fornece não só uma estimativa do potencial protetor de compostos químicos, como também se aproxima de uma avaliação de risco para o homem, pois a distância filogenética entre as espécies é pequena. A ampliação de estudos sobre a atividade protetora dos cogumelos auxiliará na identificação de novos compostos para proteger cada vez mais os indivíduos expostos a diferentes agentes mutagênicos, prevenindo, assim, a formação de doenças neoplásicas.

Tabela 2 - Antimutagenicidade ou antigenotoxicidade de diferentes espécies de cogumelos

MN: micronúcleo

Uma explicação para a escassez de estudos sobre antimutagenicidade de cogumelos em organismos eucariotos é que a interpretação dos resultados geralmente é complexa, pois, segundo Gebhart (1992), os agentes antimutagênicos geralmente não exercem seus efeitos protetores por meio de um único mecanismo de ação.

Os resultados in vitro de Miyaji (2001), juntamente com os achados in vivo de Lima et al. (2001), ambos utilizando o teste do Micronúcleo, mostram que extratos aquosos do cogumelo Shiitake atuam protegendo as células de mamíferos dos efeitos de alguns agentes alquilantes como o metilmetanosulfonato, a ciclofosfamida e a etilnitrosouréia. Os resultados obtidos pelos autores não permitiram determinar se o mecanismo de ação do extrato de Shiitake era a desmutagênese ou a bioantimutagênese.

No mecanismo de desmutagênese, determinados fatores atuam diretamente no agente mutagênico ou em seus precursores, inativando-os antes desses atuarem sobre o DNA. No mecanismo de bioantimutagênese, os fatores atuam sobre processos de mutagênese ou de reparo de DNA danificado, levando à redução da freqüência de mutações (MORITA et al., 1978; KURODA et al., 1992).

Gebhart (1992) relatou que o modo de aplicação dos antimutágenos em relação à exposição das células alvos ao agente mutagênico (pré-tratamento, tratamento 
simultâneo ou pós-tratamento) é uma das maiores incertezas nos estudos de antimutagênese e que sua escolha pode ser uma ferramenta útil para a identificação dos mecanismos envolvidos nos processos antimutagênicos.

Miyaji (2001), utilizando o ensaio do Cometa, discute os achados de redução efetiva ou moderada da genotoxicidade do MMS, na condição de pré-tratamento das células HEp-2 com o extrato aquoso do cogumelo Shiitake com base nas observações de Kuroda et al. (1992), levantando a hipótese de que o cogumelo possa ter induzido algumas enzimas, as quais atuaram como inativadoras metabólicas do agente mutagênico, tendo possivelmente ocorrido o mecanismo de bioantimutagênese. Outra hipótese é a de que os componentes celulares possam ter capturado o MMS ou o próprio extrato tê-lo, de alguma forma, inativado. Neste caso, o mecanismo ocorrido seria a desmutagênese.

A atividade protetora exercida pelo cogumelo Shiitake nas células humanas foi mais efetiva quando o extrato foi preparado a $60^{\circ} \mathrm{C}$ (MIYAJI, 2001). Este resultado não encontra amparo no achados de Kada (1981) apudGruter et al. (1991), de que o fator antimutagênico ativo detectado no cogumelo Lentinula edodes parece ser termo-lábil. No entanto, Grüter et al. (1991) mostraram que em diversos cogumelos há fatores resistentes ao calor que reduzem a mutagenicidade de agentes carcinogênicos potentes como a aflatoxina $B_{1}$ e 0 benzo(a)pireno em S. typhimurium.

De acordo com Lehmann et al. (2000), um outro ponto crucial a ser considerado é o fato de que alguns moduladores que exercem efeitos protetores numa dada situação, podem se tornar deletérios quando o agente mutagênico ou o parâmetro sob análise é modificado. A análise de sistemas-testes distintos, como o teste do Micronúcleo ou o do Cometa, pode levar a respostas diferentes das células, pois o teste do Cometa é considerado mais sensível para detectar danos e/ou alterações na conformação do DNA devido a agentes genotóxicos, do que o teste do Micronúcleo, que detecta atividades clastogênicas ou aneugênicas do composto avaliado. Além disso, quando ocorre o processo de reparo por excisão, normalmente não é gerado um MN, enquanto, que, segundo Speit et al. (1996), a formação de quebra de cadeia durante os processos de reparo por excisão pode também levar à migração do DNA no ensaio do Cometa.

Lima et al. (2001) detectaram atividade antimutagênica in vivo do cogumelo Shiitake frente à etilnitrosouréia e, em Miyaji (2001), esta atividade foi detectada in vitro frente ao MMS, ambos agentes alquilantes. Portanto, para um melhor entendimento do mecanismo protetor do extrato de Shiitake, torna-se necessário efetuar experimentos com outros tipos de agentes mutagênicos, preferencialmente não alquilantes, pois os dados existentes até o momento, além de serem escassos, são em relação a este tipo de composto químico.

A prevenção do câncer e de outras doenças relacionadas pode ser realizada tanto por impedimento da exposição a mutágenos/carcinógenos reconhecidos, como por favorecimento do consumo de fatores protetores ou por fortalecimento dos mecanismos de defesa fisiológica (DE FLORA, 1998). Em relação ao cogumelo do Shiitake é prematura a recomendação quanto a eventuais riscos ou benefícios para a saúde humana, pois estudos adicionais com ênfase em outras temperaturas e nos compostos ativos dos extratos desse cogumelo são necessários para a confirmação da mutagenicidade ou antimutagenicidade relatadas até o momento.

\section{Agradecimentos}

As autoras agradecem à Srta. Angela Mehta pela cuidadosa leitura e revisão do Abstract e à CAPES, FAPESP e UEL pelos recursos destinados à dissertação de mestrado.

\section{Referências}

CHANG, R. Functional properties of edible mushrooms. Nutrition Reviews, v.54, n.11, p.91-93, 1996.

DE FLORA, S. Mechanisms of inhibitors of mutagenesis and carcinogenesis. Mutation Research, v.402, p.151-158, 1998.

DE MARINI, D. M. Dietary interventions of human carcinogenesis. Mutation Research, v.400, p.457-465, 1998.

FDA (Us Food and Drug Administration). Redbook 2000 - Toxicological principles for the safety of food ingredients. Disponível em: <http://www.fda.gov>. Acesso em: 25 out. 2001.

GEBHART, E. Anticlastogenicity in cultured mammalian cells. Mutation Research, v.267, p.211-220, 1992.

GODOY, L. P. Antimutagenicidade do Cogumelo do Sol (Agaricus blazei M. - ABL 99/26) em cultura de células Hep-2. 2000. 32p. Monografia - Universidade Estadual de Londrina, Londrina.

GRUTER, A.; FRIEDERICH, U.; WÜRGLER, F. E. Antimutagenic effects of mushrooms. Mutation Research, v.231, p.43-249, 1990.

GRUTER, A.; FRIEDERICH, U.; WÜRGLER, F. E. The mutagenicity of edible mushroom in a histidineindependent bacterial test system. Food and Chemical Toxicology, v.29, n.3, p.159-165, 1991.

HANNAN, M. A. et al. Mutagenic and antimutagenic factor(s) extracted from a desert mushroom using different solvents. Mutagenesis, v.4, p.111-114, 1989.

HARTMAN, P. E.; SHANKEL, D. M. Antimutagens and anticarcinogens: a survey of putative interceptor molecules. Environmental and Molecular Mutagenesis, v.15, p.145-182, 1990.

HAYATSU, H.; ARIMOTO, S.; NEGISHI, T. Dietary inhibitors of mutagenesis and carcinogenesis. Mutation Research, v.202, p.429-446, 1988.

HEDDLE, J. A. et al. The induction of micronuclei as a measure of genotixicity. Mutation Research, v.123, p.61-118, 1983. 
JONG, S. C.; BIRMINGHAM, J. M. Medicinal and therapeutic value of the Shiitake mushroom. Advances in Applied Microbiology, v.39, p.154-184, 1993.

KLAUDE, M. et al. The Comet Assay: mechanisms and technical considerations. Mutation Research, v.363, p.89-96, 1996.

KURASHIGUE, S.; AZUKAWA, Y.; ENDO, F. Effects of Lentinus edodes, Grifola frondosa, Pleurotus ostreatus administrations on cancer outbreak and activities of macrofages and lymphocytes in mice treated with a carcinogen, $\mathrm{N}$-butyl $\mathrm{N}$-butanol nitrosamine. Immunopharmacology and Immunotoxicology, v.19, n.2, p. 175-183, 1997.

KURODA, Y. et al. Antimutagenicity in cultured mammalian cells. Mutation Research, v.267, p.201-209, 1992.

LEHMANN, M. et al. Interference of Tannic Acid on the genotoxicity of Mitomicyn C, Methylmethanesulfonate and Nitrogen mustard in somatic cells of Drosophila melanogaster. Environmental and Molecular Mutagenesis, v.36, p.195-200, 2000.

LIMA, P.L.A.; DELMANTO, R.D.; SUGUI, M.M.; EIRA, A.F.; SALVADORI, D.M.F, SPEIT, G.; RIBEIRO, L.R. Lentinula edodes (Berk) Pegler (Shiitake) modulates genotoxic and mutagenic effects induced by alkylating agents in vivo. Mutation Research, v. 496, p. 23-32, 2001.

MAKI, C. S. Avaliação da inibição de Candida albicans pelo cogumelo comestível Lentinula edodes (Shiitake). 1999. Dissertação (Mestrado) - Universidade Estadual de Londrina, Londrina, 1999.

MENOLI, R. C. R. N. et al. Antimutagenic effects of the mushroom Agaricus blazei Murill extracts on V79 cells. Mutation Research, v. 496, p.5-13, 2001.

MINATO, K. et al. Autolysis of Lentinan, an antitumor polysaccharide, during storage of Lentinus edodes, Shiitake mushroom. Journal of Agricultural Chemistry, v.47, p.1530-1532, 1999.

MIYAJI, C. K. Avaliação da mutagenicidade e/ou antimutagenicidade de extratos do cogumelo Shiitake (Lentinula edodes (Berk.) Pegler) em cultura de células Hep-2 in vivo. 2001. Dissertação (Mestrado) - Universidade Estadual de Londrina, Londrina, - PR.

MIZUNO, T. Shiitake, Lentinus edodes: functional properties for medicinal and food purposes. Food Reviews International, v.11, n.1, p.111-128, 1995a.

MIZUNO, T. Bioactive biomolecules of mushrooms: food function and medicinal effects of mushroom fungi. Food Reviews International, v.11, n.1, p.7-21, 1995b.

MOLINA, F. I. et al. Molecular evidence supports the separation of Lentinula edodes from Lentinus and related genera. Canadian Journal of Botany, v.70, p.2446-2452, 1992.

MORALES, P. et al. A study of the mutagenicity of some commercially canned Spanish mushrooms. Food and Chemical Toxicology, v.9, p.607-611, 1990.

MORITA, K.; HARA, M.; KADA, T. Studies on natural desmutagens: Screening for vegetable and fruit factors active in inativation of mutagenic pyrolysis products from amino acids. Agricultural and Biological Chemistry, v.42, p.1235-1238, 1978.

ODIN, A. P. Vitamins as antimutagens: advantages and some possible mechanisms of antimutagenic action. Mutation Research, v.386, p.39-67, 1997.

OLIVEIRA, J. M. Efeito protetor do extrato aquoso do Cogumelo-do-Sol (Agaricus blazei Murril, ABL99/26) na genotoxicidade do metilmetanosulfonato em células V79. 2001. Dissertação (Mestrado) - Universidade Estadual de Londrina, Londrina - PR.

POOL-ZOBEL, B. L. et al. Consumption of vegetables reduces genetic damage in humans: first results of a human intervention trial with carotenoid-rich foods. Carcinogenesis: v.18, n.9, p.1847-1850, 1997.

RABELLO-GAY, M. N. Teste do Micronúcleo em medula óssea. In: RABELLO-GAY, M. N.; RODRÍGUEZ, M. A. L. R.; MONTELEONE-NETO, R. Mutagênese, Teratogênese e Carcinogênese. Métodos e critérios de avaliação, Ribeirão Preto - SP. Sociedade Brasileira de Genética, 1991, p. 83-90, 1991.

RAMEL, C. et al. ICPEMC - Inhibitors of mutagens and their relevance to carcinogenesis. Mutation Research, v.168, p.47-65, 1986.

ROMPELBERG, C. J. M. et al. Antimutagenicity of eugenol in the rodent bone marrow micronucleus test. Mutation Research, v.356, p.69-75. 1995.

SPEIT, G. et al. Detection of DNA effects in human cells with the comet assay and their relevance for mutagenesis. Toxicology Letters, v.88, p.91-98, 1996.

SPEIT, G.; HARTMANN, A. The Comet Assay (Single Cell Gel Test) - A sensitive genotoxicity test for the detection of DNA damage and repair. In:HENDERSON, D. S. (Ed.). Methods in Molecular Biology, 113 DNArepair protocols: Eukaryotic Systems. Totowa, NY: Humana Press, 1999. p. 203-212.

STERNER, O. et al. Mutagens in larger fungi. I. 48 species screened for mutagenic activity in the Salmonella/microsome assay. Mutation Research, v.101, n.4, p.269-281, 1982a.

STERNER, O. et al. Mutagens in larger fungi. II. The mutagenicity ofcommercial pickled Lactarius necator in the Salmonella assay. Mutation Research, v.104, n.45, p.233-237, 1982b.

TOTH, B.; ERIKSON, J. Cancer induction in mice by feeding of the uncooked culticated mushroom of commerce Agaricus bisporus. Cancer Research, v.46, p.4007-4011, 1986.

WASSER, S. P.; WEIS, A. L. Therapeutic effects of substances occurring in higher basidiomycetes mushrooms: a modern perspective. Critical Reviews in Immunology, v.19, n.65-96, 1999.

WATTEMBERG, L. W., Chemoprevention of cancer. Cancer Research, v.45, p.1-8, 1985.

WATERS, M. D. et al. Antimutagenic profiles for some model compounds. Mutation Research, v.238, p.57-85, 1990. 
Tabela 1 - Mutagenicidade ou genotoxicidade de diferentes espécies de cogumelos

HPRT: hipoxantina fosforribosil transferase; MN: micronúcleo; M: atividade moderada. 